\title{
A Solution for Environmental Constrained Economic Dispatch Problems using Honey Bee Algorithm
}

\author{
H. Vennila \\ Department of Electrical and Electronics \\ Engineering \\ Noorul Islam University, Kumaracoil \\ Tamil Nadu, INDIA
}

\author{
T. Ruban Deva Prakash, PhD \\ Department of Electrical and Electronics \\ Engineering \\ Noorul Islam University \\ Kumaracoil \\ Tamil Nadu, INDIA
}

\begin{abstract}
In this paper, honey bee algorithm is proposed to optimise the economic and emission dispatch problems in power systems effectively. This optimization method focuses the global solution in a sense that a generation company need carry out the cost reduction and emission reduction under competitive environment. In recent years increasing of thermal power plants air pollution and concentration of carbon dioxide emission leads to the global warming. This paper solves the economic dispatch and the combined economic and emission dispatch problem considering both ramp rate and valve point loading effect. To demonstrate the effectiveness of the proposed method Economic \& Emission dispatch problems are tested in 6 bus and 10 unit test system and comparisons was made with other optimization techniques.
\end{abstract}

\section{Keyword}

Honey Bee Algorithm, Economic Dispatch, Emission.

\section{INTRODUCTION}

The sizes of electric power systems are increasing rapidly to meet the energy requirements. A number of power plants are connected in parallel to supply the system load by interconnection of power stations. With the development of integrated power systems it becomes necessary to operate the plant units most economically. The economic scheduling of generators aims to guarantee at all times the optimum combination of generators connected to the system to supply the load demand [1]. For a power system to return a profit on the capital invested, proper operation is very important in operating the system for any load condition so that the cost of delivered power is minimum. To determine the economic distribution, operating costs of the unit must be expressed in terms of the power output. Generally the operating cost is expressed as a quadratic function of the power output.

Nowadays, a large part of energy production is done with thermal sources. Thermal electrical power generating is one of the most important sources of carbon dioxide $\left(\mathrm{CO}_{2}\right)$, Sulphur dioxide $\left(\mathrm{SO}_{2}\right)$ and nitrogen oxides $\left(\mathrm{NO}_{2}\right)$ which create atmospheric solution [2].The clean Air Act Amendments of 1990 mandates that the electric utility industry should reduce its $\mathrm{SO}_{2}$ emission by 10 million ton/year and the $\mathrm{NO}_{\mathrm{x}}$ by 2 million ton/year from 1980 level [3].

Combined economic and emission dispatch has been proposed in the field of power generation dispatch, which simultaneously minimises both fuel cost and pollutant emissions. When the emission is minimized the fuel cost may be unacceptably high or when the fuel cost is minimised the emission may be high.

Several Optimization techniques such as lambda iteration ,linear programming(LP), non-linear programming(NLP), quadratic programming $(\mathrm{QP})$ and interior point method(IPM)[4], the GA[5], GA Combined with Simulated annealing[6] are employed for solving the economic dispatch problem.

When environmental constraints are augmented to the basic economic dispatch problem, ED becomes a multi-objective optimization problem. Many methods are used for solving the multi-objective economic dispatch using weighting factor approach [7], €-constraint method [8],goal programming approach[9] etc. Weight factor approach and $€$-constraint approach are time consuming and tends to find weak solutions and goal programming approach requires a priori knowledge about the shape of the search space.

In this paper, Honey Bee Algorithm was used to find the solution of Economic and Emission dispatch problems. It has been used for Electronic design, digital filter optimisation, and Robot control.

\section{PROBLEM FORMULATION}

Economic load dispatch pertains to optimum generation scheduling of available generators in an inter connected power system to minimise the cost of generation subject to relevant system constraints

\subsection{Economic Dispatch}

a.Fuel Cost minimisation

$$
\text { Min } \left.\mathrm{C}_{\mathrm{T}}=\sum F i(P g i)_{\mathrm{i}}\right)
$$

$$
\sum_{\mathrm{C}}\left(\mathrm{a}_{\mathrm{i}} \mathrm{P}_{\mathrm{g}}{ }_{\mathrm{i}}^{2}+\mathrm{b}_{\mathrm{i}} \mathrm{P}_{\mathrm{gi}}+\mathrm{c}_{\mathrm{i}}\right)
$$

Where $\mathrm{C}_{\mathrm{T}}$ is the total generation $\operatorname{cost}(\$ / \mathrm{hr}), F_{i}$ is the fuel-cost function of generator $\mathrm{i}(\$ / \mathrm{hr}), \mathrm{n}$ is the number of units, $\mathrm{P}_{\mathrm{gi}}$ is the real power generation of generator $i$ in $\mathrm{MW}$, and $\mathrm{a}_{\mathrm{i}}, \mathrm{b}_{\mathrm{i}}, \mathrm{c}_{\mathrm{i}}$ are the cost coefficients of unit $i$.

The objective function is subject to equality and inequality constraints such as,

$$
\begin{gathered}
\sum_{\text {gi }}=\mathrm{P}_{\mathrm{D}}+\mathrm{P}_{\mathrm{L}} \\
\mathrm{P}_{\text {gimin }} \leq \mathrm{P}_{\text {gi }} \leq \mathrm{P}_{\text {gimax }} \\
\text { wherei }=1,2, \ldots . \mathrm{n}
\end{gathered}
$$


$\mathrm{P}_{\mathrm{D}}=$ Power demand in $\mathrm{MW}$

$\mathrm{P}_{\mathrm{L}=\text { Network loss in } \mathrm{MW}}$

$\mathrm{P}_{\text {gimin }}, \mathrm{P}_{\text {gimax }}=$ Minimum and Maximum power generation limit of generator i.

b.Objective function subject to Ramp rate limits

Considering Ramp rate limits, real power generation limits are modified as,

$$
\begin{aligned}
& \operatorname{Max}\left(\mathrm{P}_{\text {gimin }}, \mathrm{P}_{\mathrm{g} \mathrm{i}}{ }^{0}-\mathrm{DR}_{\mathrm{i}}\right) \leq \mathrm{P}_{\mathrm{gi}} \leq \min \left(\mathrm{P}_{\text {gimax }}, \mathrm{P}_{\mathrm{g} i \mathrm{i}}^{0}+\mathrm{UR}_{\mathrm{i}}\right) \\
& \text { where } \mathrm{i}=1,2, \ldots \ldots . . \mathrm{n}
\end{aligned}
$$

$\mathrm{P}_{\mathrm{g}}{ }_{\mathrm{i}}=$ Previous operating point of generator $\mathrm{i}$

$\mathrm{DR}_{\mathrm{i}}, \mathrm{UR}_{\mathrm{i}}=$ Down and $\mathrm{Up}$ ramp rate limits of the generator $\mathrm{i}$.

\subsection{Considering Valve point loading effect}

The objective function is given by

$$
\mathrm{F}_{\mathrm{i}}\left(\mathrm{P}_{\mathrm{gi}}\right)=\mathrm{a}_{\mathrm{i}} \mathrm{P}_{\mathrm{g}}{ }_{\mathrm{i}}^{2}+\mathrm{b}_{\mathrm{i}} \mathrm{P}_{\mathrm{gi}}+\mathrm{c}_{\mathrm{i}}+|\operatorname{disin}(\operatorname{ei}(P g i m i n-P g i))|
$$

Where, $d_{i}, e_{i}=$ Valve point loading constants

Subject to the constraints (2-4).

\section{Combined Economic and Emission Dispatch}

The amount of emission from a fossil- based thermal generator unit depends on the amount of power generated by the unit. But this emission is not considered in pure ED problem. Considering emission control the objective function is formulated as,

$$
E\left(\mathrm{P}_{\mathrm{g}}\right)=\sum\left(\alpha_{\mathrm{i}} \mathrm{P}_{\mathrm{g}}{ }_{\mathrm{i}}^{2}+\beta_{\mathrm{i}} \mathrm{P}_{\mathrm{gi}}+\gamma_{\mathrm{i}}\right) \times 10^{2}+\mathrm{x}_{\mathrm{i}} \exp \left(\mathrm{y}_{\mathrm{i}} \mathrm{P}_{\mathrm{gi}}\right)
$$

Where $\alpha_{\mathrm{i}}, \beta_{\mathrm{i}}, \gamma_{\mathrm{i}}, \mathrm{x}_{\mathrm{i}}, \mathrm{y}_{\mathrm{i}}=$ emission coefficients of unit $\mathrm{i}$

Combined economic and emission dispatch problem is formulated as

$\Psi=\xi_{1} * F_{i}(\mathrm{P})+\zeta_{2} * \mathrm{~K} * E$

$$
\xi_{1}, \xi_{2}=\text { weight factors. }
$$

Subject to constraints (2-4).

\section{Proposed Honey Bee Algorithm}

\subsection{Bees in nature}

A colony of honey bees can extend itself over long distances in order to exploit a large number of food sources at the same time [10]. A colony prospers by deploying its foragers to good yields. In principle, flower patches with plentiful amounts of nectar or pollen that can be collected with less effort should be visited by more bees, whereas patches with less nector or pollen should receive fewer bees[11,12].During the harvesting season, a colony continues its exploration, keeping a percentage of the population as scout bees. When they return to the hive, those scout bees that found a patch rated above a certain quality threshold deposit their nector or pollen and go to the "dance floor" to perform a dance known as the "waggle dance" $[10]$.

This mysterious dance is essential for colony communication, and contains three pieces of information regarding a flower patch: the direction in which it will be found, the distance from the hive and the quality rating [12]. This information helps the colony to send its bees to flower patches precisely, without using guides or maps. Each individual's knowledge of the outside environment is gleaned solely from the waggle dance. This dance enables the colony to evaluate the relative merit of different patches according to both the quality of the food they provide and the amount of energy needed to harvest it [12]. After waggle dancing on the dance floor, the dance (i.e. the scout bee) goes back to the flower patch with follower bees that were waiting inside the hive .More follower bees are sent to more promising patches. This allows the colony to gather food quickly and efficiently.

While harvesting from a patch, the bees monitor its food level. This is necessary to decide upon the next waggle dance when they return to the hive [12].If the patch is still good enough as a food source and it will be advertised in the waggle dance and more bees will be recruited to that source.

\subsection{Proposed Bees Algorithm}

The Bees Algorithm is an optimisation algorithm inspired by the natural foraging behaviour of honey bees to find the optimal solution. Fig.2 shows the simplest form of honey bee algorithm. This algorithm requires a number of parameters to be set namely: number of scout bees (n), number of sites selected out of $n$ visited sites (m), number of best sites out of $m$ selected sites (e), number of bees recruited for best e sites (ne), number of bees recruited for the worst sites (nw), initial size of patches (ngh) which includes sites and its neighbourhood and stopping criterion. The algorithm starts with the $\mathrm{n}$ scout bees being placed randomly in the search space. The fitness's of the sites visited by the scout bees are evaluated in step2.

1.Initialise population with random solutions.

2.Evaluate fitness of the population.

3.While(stopping criterion not met)

// Forming new population

4.Select sites for neighbourhood search

5. Recruit bees for selected sites

(more bees for best e sites) and evaluate fitnesses.

6. Select the fittest bee from each patch.

7. Assign remaining bees to search randomly and evaluate their fitnesses.

8. End While.

\section{Fig1. Honey bee Algorithm for Optimisation}

In step 4, bees that have the highest fitnesses are chosen as " selected bees" and sites visited by them are chosen for neighbourhood search. Then, in steps 5 and 6 , the algorithm conducts searches in the neighbourhood of the selected sites, assigning more bees to search near to rhe best e sites. The bees can be chosen directly according to the fitnesses associated with the sites they are visiting. Alternatively, the fitness values are used to determine the probability of the bees being selected. Searches in the neighbourhood of the best e sites which represent more promising solutions are made more detailed by recruiting more bees to follow them than the other selected bees. Together with scouting, this differential recruitment is a key operation of the Bees Algorithm.

However, in step 6 , for each patch only the bee with the highest fitness will be selected to form the next bee population. This restriction is introduced here to reduce the number of points to be explored. In step 7, the remaining bees in the population are assigned randomly around the search space scouting for new potential solutions. These steps are repeated until a stopping criterion is met. At the end of each iteration, the colony will have two parts to its new populationrepresentatives from each selected patch and other scout bees assigned to conduct random searches. 


\subsection{Parameters used in honey bee Algorithm}

Number of scout bees- 100

Number of sites selected for neighbouring search-10

Number of bees recruited for best e sites, m-3

Number of bees recruited for the other (m-e) selected sites-7

Number of iterations- 50

\section{SIMULATION RESULTS AND DISCUSSIONS}

\begin{tabular}{|c|c|c|c|}
\hline Generator & \multicolumn{3}{|c|}{ Methods } \\
\hline $\begin{array}{l}\text { Output in } \\
\text { MW }\end{array}$ & HB & PSO & GA \\
\hline $\mathrm{P} 1$ & 446.787 & 447.497 & 474.8066 \\
\hline $\mathrm{P} 2$ & 173.2531 & 173.3221 & 178.6363 \\
\hline P3 & 263.0745 & 263.4745 & 262.2089 \\
\hline $\mathrm{P} 4$ & 138.8594 & 139.0594 & .2826 \\
\hline $\mathrm{P} 5$ & 165.2761 & 165.4761 & 151.9039 \\
\hline $\mathrm{P} 6$ & 87.124 & 87.128 & 74.1812 \\
\hline $\begin{array}{c}\text { Total } \\
\text { Power(MW) }\end{array}$ & 1274.374 & 1275.957 & 1276.0195 \\
\hline $\begin{array}{l}\text { Generation } \\
\operatorname{Cost}(\$ / \mathrm{h})\end{array}$ & 15,423 & 15,450 & 15,459 \\
\hline
\end{tabular}

\subsection{Description of the test systems}

To validate the proposed Honey Bee Algorithm, it is tested with two test systems having nonconvex solution spaces. The first test system consists if six generators with a total load of 1263MW[9].All the generators are having ramp rate limits. The best generation cost reported until now is $\$ 15,423 / \mathrm{h}$. The previous best generation cost was $\$ 15,450$ [15].

The second system consists of ten generators with multifuel options and valve-point effects[14]. The first generator is having two fuel options, and the remaining generators are having three fuel options. The best generation cost reported so far is $\$ 624.1273[15]$.

The combined Economic and Emission dispatch problem was solved for six generator system . The generator emission coefficients are taken from ref[16].

\subsection{Convergence Test}

The convergence test is performed in order to find out the effectiveness of the quickness of the Honey bees Algorithm in terms of the number of main PSO iterations.The Proposed honey bee algorithm is applied in a 6-generator system and the obtained convergence characteristics are given in Fig1. The output of generation cost is given in Table1 . From the output, it is evident that Honey bee Algorithm is for more superior when compared with PSO and GA algorithms. The worse experience component provides the extra diversification which causes this superiority.

In IGAMU [15], multiple fuel option and valve point loading are combined to resolve the economic dispatch problems. IGAMU is faster and yields quality solutions compared to conventional genetic algorithm with multiplier upgrading[CGAMU][15]. The characteristics of solution to the EDVLMF problem using $\mathrm{HB}$ and convergence characteristics are compared with that of IGAMU method illustrated in Fig2 and Table[2].

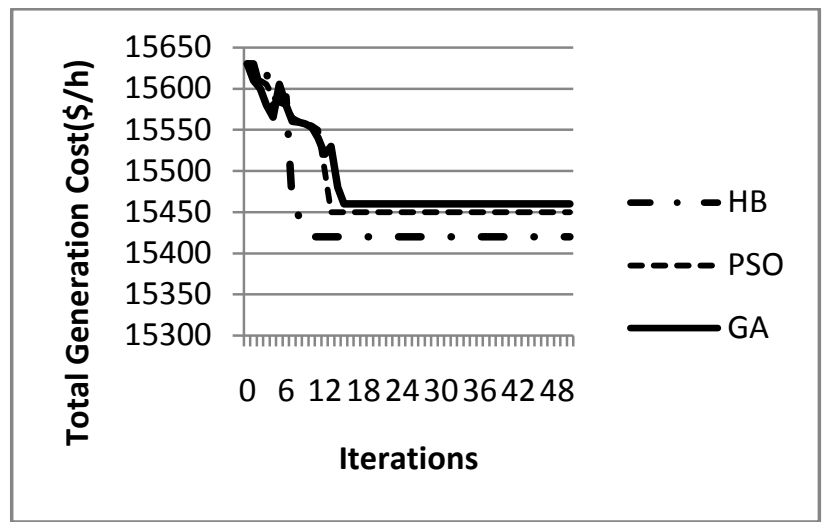

Fig.2. Cost comparison between three algorithms for six generator system

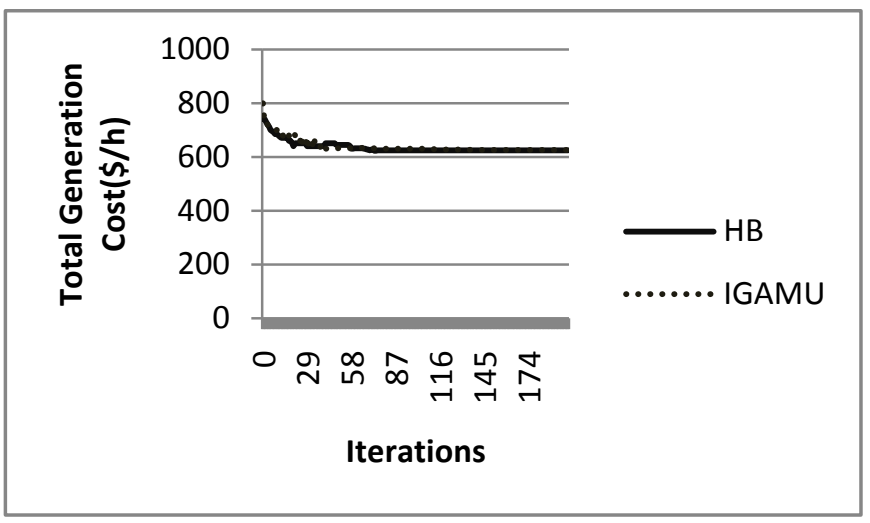

Fig.3. Cost comparison between HB and IGAMU for ten generator system.

\begin{tabular}{|c|c|c|c|}
\hline \multirow{2}{*}{$\begin{array}{l}\text { Generator } \\
\text { Power } \\
\text { Output in } \\
\text { MW }\end{array}$} & \multicolumn{3}{|c|}{ Methods } \\
\hline & $\mathrm{HB}$ & PSO & GA \\
\hline $\mathrm{P} 1$ & 446.787 & 447.497 & 474.8066 \\
\hline $\mathrm{P} 2$ & 173.2531 & 173.3221 & 178.6363 \\
\hline P3 & 263.0745 & 263.4745 & 262.2089 \\
\hline $\mathrm{P} 4$ & 138.8594 & 139.0594 & .2826 \\
\hline P5 & 165.2761 & 165.4761 & 151.9039 \\
\hline P6 & 87.124 & 87.128 & 74.1812 \\
\hline $\begin{array}{c}\text { Total } \\
\text { Power(MW) }\end{array}$ & 1274.374 & 1275.957 & 1276.0195 \\
\hline $\begin{array}{l}\text { Generation } \\
\text { Cost }(\$ / h)\end{array}$ & 15,423 & 15,450 & 15,459 \\
\hline
\end{tabular}

Table: 1

Output for Six Generator System 
Table:2

Output for Ten Generator System

\begin{tabular}{|c|c|c|}
\hline \multirow{2}{*}{ Units } & HB & IGAMU \\
\cline { 2 - 3 } & PG(MW) & PG(MW) \\
\hline 1. & 219.1201 & 210.1261 \\
2. & 211.0645 & 211.1645 \\
3. & 280.7512 & 280.6572 \\
4. & 237.475 & 238.4770 \\
5. & 276.9176 & 276.4176 \\
6. & 240.9672 & 240.4672 \\
7. & 287.7419 & 287.7399 \\
8. & 239.7584 & 240.7614 \\
9. & 430.337 & 429.3370 \\
10. & 275.8548 & 275.8518 \\
\hline Total Power & $\mathbf{2 7 0 0}$ & 2700 \\
(MW) & & \\
\hline Total Cost $(\$)$ & 624.0526 & 624.5178 \\
\hline
\end{tabular}

Table:3

Cost Comparison after 50 trials

\begin{tabular}{|c|c|c|c|}
\hline \multirow{2}{*}{$\begin{array}{c}\text { Total } \\
\text { Generation } \\
\text { Cost }(\$ / \mathrm{h})\end{array}$} & \multicolumn{3}{|c|}{ Methods } \\
\hline & GA & PSO & $\mathrm{HB}$ \\
\hline Minimum & 15459 & 15450 & 15423 \\
\hline Maximum & 15524 & 15492 & 15426 \\
\hline Average & 15469 & 15454 & 15421 \\
\hline
\end{tabular}

Table:4

Results of best fuel cost for the $\mathrm{HB}$ and 3 approaches

\begin{tabular}{|c|c|c|c|c|}
\hline Unit & HB & {$[16]$} & {$[17]$} & {$[18]$} \\
\hline 1. & 0.0965 & 0.1281 & 0.1086 & 0.1168 \\
\hline 2. & 0.2412 & 0.2702 & 0.3056 & 0.3165 \\
\hline 3. & 0.2360 & 0.5552 & 0.5818 & 0.5441 \\
\hline 4. & 0.9653 & 1.0053 & 0.9846 & 0.9447 \\
\hline 5. & 0.4925 & 0.4544 & 0.5288 & 0.5498 \\
\hline 6. & 0.3465 & 0.4453 & 0.3584 & 0.3964 \\
\hline Best Cost & $\mathbf{5 9 8 . 1 3}$ & 606.66 & 607.807 & 608.245 \\
\hline Emission & 0.2203 & 0.2207 & 0.22015 & $\mathbf{0 . 2 1 6 6 4}$ \\
\hline
\end{tabular}

Table 5:

Results of best emission for $\mathrm{HB}$ and 3 approaches

\begin{tabular}{|c|c|c|c|c|}
\hline Unit & HB & {$[16]$} & {$[17]$} & {$[18]$} \\
\hline 1. & 0.3842 & 0.3713 & 0.4043 & 0.4113 \\
\hline 2. & 0.4350 & 0.4665 & 0.4525 & 0.4591 \\
\hline 3. & 0.5167 & 0.5642 & 0.5525 & 0.5117 \\
\hline 4. & 0.2975 & 0.3650 & 0.4079 & 0.3724 \\
\hline 5. & 0.5395 & 0.5223 & 0.5468 & 0.5810 \\
\hline 6. & 0.5462 & 0.5783 & 0.5005 & 0.5304 \\
\hline Cost & $\mathbf{6 4 1 . 3 6}$ & 648.01 & 642.603 & 647.251 \\
\hline $\begin{array}{c}\text { Best } \\
\text { Emission }\end{array}$ & 0.1936 & 0.1945 & $\mathbf{0 . 1 9 4 2}$ & 0.1943 \\
\hline
\end{tabular}

Table:6

Combined Economic and Emission dispatch using HB

\begin{tabular}{|c|c|c|c|c|}
\hline Unit & HB & {$[16]$} & {$[17]$} & {$[18]$} \\
\hline 1. & 0.2165 & 0.1761 & 0.2594 & 0.2699 \\
\hline 2. & 0.3178 & 0.2818 & 0.3848 & 0.3885 \\
\hline 3. & 0.5671 & 0.5407 & 0.5645 & 0.5645 \\
\hline 4. & 0.6839 & 0.7696 & 0.7030 & 0.6570 \\
\hline 5. & 0.6014 & 0.6501 & 0.5431 & 0.5441 \\
\hline 6. & 0.3953 & 0.4456 & 0.4091 & 0.4398 \\
\hline Cost & $\mathbf{6 0 9 . 5 6 3}$ & 612.35 & 616.06 & 618.68 \\
\hline Emission & $\mathbf{0 . 1 9 4 3}$ & 0.2074 & 0.2011 & 0.1994 \\
\hline
\end{tabular}

\subsection{Comparisons of the solutions}

By comparing the best power output of the six generator system using $\mathrm{HB}$ algorithm, GA and PSO

it is seen that in $\mathrm{HB}$ algorithm the generation cost is minimum. Thus the HB algorithm has multiple advantages of best generation schedule with minimum network loss, keeping generation costs viable.

\subsection{Robustness Test}

Multiple iterations with different initializations are required for determining the performance of heuristic algorithms. For these algorithms to be robust, they should give constant results in all iterations.

The results of 50 iterations with the six bus system are compared and shown in Table 3 which clearly highlights the superiority of the Honey Bee Algorithm over GA[15]and $\mathrm{PSO}$ [15] . The maximum and average values obtained by Honey Bee Algorithm have only marginal variations from the minimum value. This reiterates the fact that $\mathrm{HB}$ is more sturdy and vigorous.

\section{CONCLUSIONS}

This paper has presented a new optimisation algorithm to solve the ED problem. The performance of the proposed algorithm is demonstrated for 6 bus and10 unit test system. The algorithm generally outperformed other techniques that were compared with the accuracy of the results obtained. The Bees algorithm found many trade off solutions. The Bees Algorithm is a computationally fast multi objective optimiser tool for complex engineering optimisation problems without any special domain information, apart from that needed to compute objective functions.

\section{REFERENCES}

[1] Ash faq Husain," Electrical Power Systems," CBS Publishers \& Distributors, New Delhi.

[2] M.Basu," A Simulated Annealing-based goal-attainment method for economic emission load dispatch of fixed head hydrothermal power systems," Electrical power and

Energy Systems, 27, 2005, pp.147-153.

[3] A.A.El-Keib, H.Ma, J.L.Hart.1994.Economic Dispatch in view of the Clean Air Act of 1990. IEEE Trans.Power Systems 9(2):972-978.

[4] P.Somasundaram and K.Kuppusamy, "Application of evolutionary programming to security constrained economic dispatch," Electrical Power and Energy Systems,27,2005,pp343-351. 
[5] D.C.Walters and G.B.Sheble,"Genetic Algorithm solution economic dispatch with valve point loading,"IEEE Trans.Power Syst., Vol.8,no.3,pp.13251332,Aug.1993.

[6] K.P.Wong and Y.W.Wong,"Genetic and genetic/Simulated annealing approaches to economic dispatch,'Proc.Inst.Elect.Eng.,Gen.,Transm.,Disrib., Vol.141,no.5,pp.507-513,Sep.1994.

[7] C.S.Chang,K.P.Wong, and B.Fan, Security-Constrained Multi-Objective generation dispatch using bicriterion global optimization, in Proc.IEE Gen Transm.Dist., Vol.142,no.4,pp.406-414,July 1995.

[8] R.Yokoyama, S.H.Bae, T.Morita and H.Sasaki, "Multi objective optimal generation dispatch based on probabily Security criteria,'IEEE Trans.Power Systems, Vol.3, no.1, pp. 317-324,Feb 1988

[9] J.Nanda, D.P.Kothari,K.S.Lingamurthy,"Economic Emission load dispatch through goal programming technigue, IEEE Trans, Energy Conversion, Vol.3,no.1,pp.26-32, March 1988.

[10] Seeley, T.D. The Wisdom of the Hive: The Social Physiology of Honey Bee Colonies, 1996(Harvard University Press, Cambridge)

[11] Bonabeau E,Dorigo $M$, and Theraulaz G.Swarm Intelligence: from Natural to Artificial Systems. Oxford University Press, New Yark,1999.
[12] Camazine S, Deneubourg J, Franks N R, Sneyel ,Theraula $G$ and Bonabeau E. Self Organisation in Biological Systems. Princeton: Princeton University Press, 2003.

[13] Z.L.Gaing," Particle swarm optimization to solving the economic dispatch considering the generator constraints," IEEE Trans.Power Syst., vol.18,no.3,pp.1187-1195,Aug.2003.

[14] N.Sinha,R.Chakrabarti, P.K.Chattopadhyay,"Evolutionary programming technicques for economic load dispatch.'IEEE Trans.Evol.Comput.,vol.7,no.1,pp.83-94,Feb.2003.

[15] K.Thanuskodi,"A New Particle Swarm Optimization Solution to Nonconvex Economic Dispatch Problems," IEEE Trans.Power Syst., vol.22,no.1.Feb2007.

[16] Hemamalini, Sishaj P.Simon," Emision constrained economic with valve point effect using Particle Swarm Optimisation," TENCON 2008.IEEE REGON 10.Conference, 19-21 November 2008 page(s): 1-6.

[17] M.Abido," Environmental/Economic Power dispatch using multi objective evolutionary algorithms,"IEEE Trans.Power Syst., Vol.18, no.4,pp.1529-1537, Nov 2003.

[18] M.A. Abido," Anovel multi objective evolutionary algorithm for environmental/economic power dispatch," Electric power system,"Electric Power System Research., vol.65,pp.71-81,2003. 